\title{
AVALIAÇÃO DA SOMATOTROPINA BOVINA RECOMBINANTE (rbST) NOS NÃO-COMPONENTES DA CARCAÇA DE CABRITOS DE TRÊS GENÓTIPOS
}

\author{
LuCiana Rodrigues ${ }^{1}$, Heraldo CÉsar GonÇALVES ${ }^{2}$, BRENDA Batista Lemos Medeiros ${ }^{3}$, \\ JAKILANE JACQUE LEAL MENEZES ${ }^{4}$, SiRLEI APARECIDA MAESTÁ ${ }^{5}$ \\ ${ }^{1}$ Doutora em Zootecnia pela Universidade Estadual Paulista Julio de Mesquita, Botucatu, SP, Brasil - llucianarr@ gmail.com \\ ${ }^{2}$ Professor Doutor da Universidade Estadual Paulista, Botucatu, SP, Brasil. \\ ${ }^{3}$ Pós Graduanda da Faculdade de Engenharia Agícola da UNICAMP, Campinas, SP. Brasil. \\ ${ }^{4}$ Professora Doutora do Instituto Federal de Educação do Ceará, Fortaleza, CE, Brasil. \\ ${ }^{5}$ Professora Doutora da Universidade Estadual Paulista, Dracena, SP, Brasil.
}

Desenvolveu-se o presente estudo com o objetivo de avaliar a somatotropina bovina recombinante (rbST) nos não-componentes da carcaça de cabritos de três genótipos. Foram utilizados 23 machos inteiros de três genótipos, sendo oito Alpino (A), quatro $1 / 2$ Boer $+1 / 2$ Alpino ( $1 / 2$ BA) e $113 / 4$ Boer + 1/4 Alpino ( $3 / 4$ BA), dos quais 12 receberam rbSTe 11controle. O hormônio de crescimento utilizado foi a somatotropina recombinante bovina (rbST) e os animais do tratamento 1 receberam o hormônio na quantidade de $0,3 \mathrm{mg} / \mathrm{kg}$ de peso vivo, a partir dos 45 dias, ajustada em intervalos de 14 dias. Os animais do tratamento 2 (controle) receberam solução salina na mesma dosagem e intervalo. Os animais $1 / 2$ BA apresentaram uma maior proporção dos não-componentes externos (cabeça, patas e pele) em relação aos da raça Alpina. Em relação aos órgãos vitais, como pulmão, rins e baço, e aos não-componentes sangue, gordura interna e gordura perirenal, os animais da raça Alpina apresentaram maiores valores em relação aos 3/4 BA. A administração da somatotropina bovina recombinante (rbST) não produziu efeito nos não-componentes da carcaça. As proporções e os pesos dos não-componentes da carcaça variaram em função dos genótipos, embora abatidos a pesos vivos semelhantes.

PALAVRAS-CHAVE: caprinos; componentes do peso vivo; hormônio de crescimento; rendimento de carcaça.

\section{EVALUATION OF RECOMBINANT BOVINE SOMATOTROPIN (rbST) ON NON- CARCASS COMPONENTS OF GOAT KIDS OF THREE GENOTYPES}

\section{ABSTRACT}

This study was developed with the aim of evaluating recombinant bovine somatotropin (rbST) on non-carcass components of goat kids of three genotypes. It was used 23 male goat kids of three genotypes, being 8 Alpine, 4 1/2 Boer $+1 / 2$ Alpine ( $1 / 2$ BA) and $113 / 4$ Boer + 1/4Alpine ( $3 / 4$ $\mathrm{BA})$, from which 12 received rbST e 11 control. The growth hormone used was the recombinant bovine somatotropin (rbST) and animals of treatment 1 received the hormone in the amount of $0.3 \mathrm{mg} / \mathrm{kg}$ live weight, from
45 days, adjusted in intervals of 14 days. Animals of treatment 2 (control) received saline solution in the same dosage and interval. The $1 / 2$ BA goats presented a higher proportion of external non-carcass components (head, feet and skin) in relation to Alpine goats. Regarding the vital organs, such as lungs, kidneys and spleen, and the noncarcass components blood, internal fat and perinephric fat, Alpine goats presented higher values than $3 / 4$ BA goats. The administration of recombinant bovine somatotropin 
(rbST) did not produce effect on proportions and weight of non-carcass components. Proportions and weight of non-carcass components varied in function of genotypes, although animals were slaughtered at similar live weight.

KEYWORDS: carcass; goats; growth hormone; live weight components.

\section{INTRODUÇÃO}

Deve-se entender que, para se alcançar máximo rendimento econômico dentro de um sistema intensivo de produção de carne, é necessário considerar o animal como um todo. Nesse sentido, OSÓRIO et al. (1996) afirmam que, ao sacrificar um animal, além da carcaça, obtêm-se outros componentes do peso vivo, que também são aproveitáveis. De acordo com DELFA et al. (1991), eles são denominados de não-componentes da carcaça, "quinto quarto", "miúdos" ou "saídas", ou seja, todos os componentes do peso vivo, exceto a carcaça.

No Nordeste do Brasil, é comum a utilização de órgãos e vísceras na culinária regional em pratos tradicionais como sarapatel e buchada. A importância dos não-componentes da carcaça não está relacionada apenas ao rendimento, mas também ao alimento que poderia consistir em alternativa para populações menos favorecidas, as quais necessitam, invariavelmente, de proteína de origem animal (MATTOS et al., 2006).

Os componentes externos da carcaça representam baixa remuneração para o produtor, mas são importantes porque exercem influência no rendimento da carcaça. CARVALHO et al. (2003) afirmam que menores participações desses componentes podem aumentar o rendimento da carcaça. Entre os componentes externos de maior importância, destacam-se a cabeça, que é desossada e a carne destinada principalmente à produção e comercialização na forma de carne moída, produção de embutidos e alimentos processados, e a pele que é vendida in natura a curtumes que a beneficia par a indústria calçadista e de vestuário. Os órgãos vitais, como fígado, rins, baço e coração também não constituem renda ao pecuarista, em comercializações via rendimento de carcaça, mas representam para os frigoríficos (MISSIO et al., 2009).

Entretanto, poucos estudos têm sido realizados em relação aos não-componentes da carcaça, provavelmente porque tais variáveis não fazem parte da carcaça comercial; todavia, pesquisas nesse ramo devem ser realizadas, já que os órgãos internos, através de um processamento adequado, podem se tornar valiosos subprodutos da indústria da carne, além de contribuírem para estudos biológicos, nutricionais e medicinais
(KIRTON et al., 1995).

Em caprinos, o peso relativo dos nãocomponentes da carcaça pode variar de 40 a $60 \%$ do peso vivo, conforme o peso vivo ao abate (AMIN et al., 2000; PEÑA et al., 2007), genótipo (CAMERON et al., 2001; KOSUM et al., 2003), sexo (GALLO et al., 1996; PEÑA et al., 2007) e nutrição (PEREZ et al., 2001; MATTOS et al., 2006).

Alguns estudos demonstram aumento no peso dos não-componentes da carcaça em animais tratados com doses crescentes de rbST (ZAINUR et al.,1989; EARLY et al., 1990). SKARDA (1998) evidenciou aumento significativo no peso relativo do fígado e rins de 16 e $19 \%$, respectivamente, em cabritos em crescimento tratados com hormônio de crescimento, além de aumento no peso absoluto do coração.

O presente trabalho foi conduzido com o objetivo de avaliar o efeito da somatotropina bovina recombinante (rbST) e genótipo nos nãocomponentes da carcaça de caprinos em crescimento.

\section{MATERIAL E MÉTODOS}

A Câmara de Ética em Experimentação Animal da Faculdade de Medicina Veterinária e Zootecnia (FMVZ) aprovou o projeto de pesquisa em 10 de agosto de 2004.

Foram utilizados 23 machos inteiros de três genótipos, sendo oito Alpino (A), quatro $1 / 2$ Boer + $1 / 2$ Alpino ( $1 / 2$ BA) e $113 / 4$ Boer + $1 / 4$ Alpino ( $3 / 4$ BA), dos quais 12 receberam rbSTe 11 placebo, distribuídos em 12 baias coletivas de acordo com o genótipo, tratamento e idade no início do experimento, afim de se evitar animais heterogêneos dentro de uma mesma baia. Os animais foram alojados em baias coletivas de piso ripado, alocadas em galpão com piso de cimento, equipadas com comedouro e bebedouro

Durante o aleitamento, o manejo alimentar constituiu-se no fornecimento de colostro de cabra tratado termicamente, seguido do fornecimento de, no máximo, 1,5 litro de leite de cabra pasteurizado, dividido em duas refeições diárias, sendo os animais desaleitados no $45^{\circ}$ dia de vida e a dieta sólida fornecida à vontade a partir do sétimo dia de vida.

O suplemento mineral específico para 
caprinos (quantidade/ quilo do produto) foi composto de $200 \mathrm{~g}$ de enxofre, $150 \mathrm{~g}$ de magnésio, $47.210 \mathrm{mg}$ de zinco, $27.000 \mathrm{mg}$ de ferro, $20.000 \mathrm{mg}$ de cobre, $1200 \mathrm{mg}$ de manganês, $1400 \mathrm{mg}$ de cobalto, $1250 \mathrm{mg}$ de iodo, $315 \mathrm{mg}$ de selênio.

A análise química da dieta completa foi realizada segundo SILVA \& QUEIROZ (2002), no Laboratório de Bromatologia da Faculdade de Medicina Veterinária e Zootecnia (FMVZ) Unesp/Botucatu - SP (Tabela 1).

Tabela 1. Composição química da dieta completa

\begin{tabular}{|c|c|}
\hline Composição química & $\begin{array}{l}\text { Dieta } \\
\text { completa }\end{array}$ \\
\hline Matéria seca (\%) & 94,59 \\
\hline Matéria mineral (\%) & 9,27 \\
\hline Proteína bruta (\%MS) & 16,47 \\
\hline Extrato etéreo (\%MS) & 3,10 \\
\hline Carboidratos totais $(\% \mathrm{MS})^{1}$ & 70,82 \\
\hline Fibra em detergente neutro (\%MS) & 25,14 \\
\hline Fibra em detergente ácido (\%MS) & 15,17 \\
\hline Carboidratos não fibrosos $(\% \mathrm{MS})^{2}$ & 38,14 \\
\hline Nutrientes digestíveis totais $(\% \mathrm{MS})^{2}$ & 73,77 \\
\hline Energia metabolizável (Mcal/kg MS) ${ }^{3}$ & 2,66 \\
\hline Cálcio (\%MS) & 1,72 \\
\hline Fósforo (\%MS) & 0,45 \\
\hline
\end{tabular}

${ }^{1}$ Obtido a partir da equação proposta por SNIFFEN et al. (1992). ${ }^{2}$ Obtidos a partir de equação proposta pelo NRC (2001). ${ }^{3}$ Obtida a partir da estimativa do NDT e pelas relações: $1 \mathrm{~kg}$ de $\mathrm{NDT}=4,409$ Mcal de $\mathrm{ED}$ e $\mathrm{EM}=81,7 \% \mathrm{ED}(\mathrm{NRC}$, 2001).

A ração foi fornecida às $7 \mathrm{~h}$ e $16 \mathrm{~h}$, com pesagem das sobras e ajuste da quantidade fornecida. $\mathrm{O}$ acompanhamento do desenvolvimento dos animais foi feito mediante pesagem semanal até atingirem a idade previamente determinada para o abate de aproximadamente 120 dias.

O hormônio de crescimento utilizado foi a somatotropina recombinante bovina (rbST) de liberação lenta, com vitamina E. Os animais do tratamento 1 receberam o hormônio por meio de seringas descartáveis de $1 \mathrm{~mL}$, via subcutânea, na região da prega ísquio-anal. A quantidade administrada de rbST foi de $0,3 \mathrm{mg} / \mathrm{kg}$ de peso vivo ajustada em intervalos de 14 dias. Os animais do tratamento 2 receberam solução salina na mesma dosagem e intervalo. A administração do hormônio iniciou-se após a desmama dos animais (aproximadamente 45 dias de idade).

Os animais foram abatidos após jejum de sólidos de $16 \mathrm{~h}$, com pesagem antes e após o jejum, para obtenção do peso vivo (PV) e peso vivo ao abate (PVA), respectivamente. A média de idade dos animais ao abate foi de $129,13 \pm 6,71$ dias.

$\mathrm{O}$ abate ocorreu de acordo com o fluxo normal do frigorífico comercial. $\mathrm{O}$ trato gastrintestinal foi esvaziado para obtenção do peso do corpo vazio (PCV), que foi calculado subtraindo-se os pesos referentes ao conteúdo gastrintestinal e ao líquido contido na bexiga e vesícula biliar do PVA. Os órgãos, vísceras e outros subprodutos obtidos após o abate dos animais foram pesados separadamente para obtenção dos nãocomponentes da carcaça (NCC). A proporção de cada NCC foi calculada em função do PVA e do PCV.

A carcaça foi obtida após a separação das mãos e dos pés na articulação carpo metacarpiana e tarso metatarsiana, respectivamente, obtendo-se o peso da carcaça quente. As carcaças foram mantidas em câmara fria com ar forçado por 24 horas, em temperatura de $5^{\circ} \mathrm{C}$, obtendo-se o peso da carcaça fria (PCF). A partir desses dados foi calculado o rendimento comercial, RC $(\%)=$ PCF/PVA x 100.

As características quantitativas e os nãocomponentes da carcaça foram analisados por análise de variância utilizando-se o modelo abaixo. O processamento das análises foi executado por meio do SAEG (UFV, 2000).

$$
\begin{aligned}
Y_{-} i j k= & \mu+T_{-} i+G_{-} j+(T * G)_{-} i j+b\left(X_{-} i j k-X^{-}\right)+e_{-} i j k \\
& \text { em que, }
\end{aligned}
$$

$Y_{i j k}=$ característica avaliada no animal $\mathrm{k}$, genótipo $\mathrm{j}$ e tratamento $\mathrm{i}$;

$\mu=$ constante inerente às observações $Y_{i j k}$;

$T_{i}=$ efeito do tratamento $\mathrm{i}$, sendo $\mathrm{i}=1-$ tratados com rbST e $\mathrm{i}=2$ - controle;

$G_{j}=$ efeito do genótipo $\mathrm{j}(\mathrm{j}=3)$, sendo $\mathrm{j}=1-$ raça Alpina, $j=2-1 / 2$ Boer $+1 / 2$ Alpina e $j=3-3 / 4$ Boer + $1 / 4$ Alpina;

$T^{*} G=$ efeito da interação do tratamento i e genótipo j;

$b=$ coeficiente de regressão linear da característica

$Y_{i j k}$ em função da idade de avaliação do animal;

$X_{i j k}=$ idade de avaliação da característica $Y_{i j k}$;

$\bar{X}=$ média da idade de avaliação da característica $Y_{i j k}$ $e_{i j k}=$ erro referente a observação $Y_{i j k}\left(0 ; \sigma_{\mathrm{e}}^{2}\right)$.

\section{RESULTADOS E DISCUSSÃO}

$\mathrm{Na}$ Tabela 2 encontram-se os valores médios de peso vivo, peso vivo ao abate, peso de corpo vazio, perda ao jejum e rendimento comercial dos três genótipos, avaliados nos dois tratamentos. Não foi observada influência da interação tratamento e genótipo para nenhuma das variáveis estudadas. Não foram observados efeitos de genótipo e tratamento para nenhuma das 
características analisadas. FATURI et al. (2002), ao avaliarem bovinos, concluíram que, quando esses parâmetros apresentam semelhança entre os grupos genéticos, há tendência de não existir diferença para as demais características quantitativas da carcaça.

Tabela 2. Médias para peso vivo (PV), peso vivo ao abate (PVA), peso de corpo vazio (PCV), perda ao jejum (PJ) e rendimento comercial (RC) de cabritos, de acordo com o tratamento e genótipo

\begin{tabular}{|c|c|c|c|c|c|c|c|c|c|}
\hline \multirow[t]{2}{*}{ Variável } & \multirow[t]{2}{*}{ Média } & \multicolumn{2}{|c|}{ Tratamento } & \multicolumn{3}{|c|}{ Genótipo $^{1}$} & \multicolumn{2}{|c|}{$\begin{array}{c}\text { Nível de } \\
\text { significância }\end{array}$} & \multirow[t]{2}{*}{$\mathrm{CV}^{3}$} \\
\hline & & controle & $\mathrm{rbST}$ & ALP & $1 / 2 \mathrm{BA}$ & $3 / 4 \mathrm{BA}$ & $\mathrm{T}$ & $\mathrm{G}$ & \\
\hline PV (kg) & 27,93 & 27,12 & 28,68 & 29,33 & 28,58 & 26,68 & NS & NS & 14,32 \\
\hline PVA (kg) & 25,89 & 25,19 & 26,53 & 27,18 & 26,43 & 24,76 & NS & NS & 15,12 \\
\hline PCV (kg) & 23,27 & 22,65 & 23,84 & 24,41 & 23,89 & 22,22 & NS & NS & 16,11 \\
\hline PJ (\%) & 7,36 & 7,25 & 7,46 & 7,31 & 7,61 & 7,30 & NS & NS & 20,64 \\
\hline $\mathrm{RC}(\%)$ & 45,50 & 45,53 & 45,47 & 45,85 & 48,74 & 44,07 & NS & NS & 8,25 \\
\hline
\end{tabular}

${ }^{1}$ ALP: raça Alpina; $1 / 2$ BA: 1/2 Boer + 1/2 Alpina; 3/4 BA: 3/4 Boer + 1/4 Alpina. ${ }^{2}$ T: tratamento; G: genótipo. ${ }^{3}$ Coeficiente de variação.NS: não significativo $(\mathrm{P}>0,05)$.

MENEZES et al. (2009), ao estudarem efeitos de genótipo nas características de carcaça, observaram valores para rendimento de carcaça de 49,16; 45,57 e 47,82\% para animais da raça Alpina, $1 / 2$ Boer + 1/2 Alpina e 3/4 Boer + 1/4 Alpina, respectivamente.

As variações na perda ao jejum podem ser atribuídas às variações no maior peso vivo ao abate. COSTA et al. (1990) verificaram valor inferior ao deste trabalho ao analisar o rendimento de carcaça de caprinos mestiços Anglo-nubianos, 2,63\% abatidos com $23,72 \mathrm{~kg}$.

$\mathrm{Na}$ Tabela 3 estão apresentados os valores médios para os não-componentes externos da carcaça de cabritos. Não foi observada influência da interação tratamento e genótipo para nenhuma das variáveis estudadas. O tratamento não influenciou nenhuma das variáveis estudadas.

Tabela 3. Médias para pesos expresso em valores absolutos e em porcentagem do peso vivo ao abate (PVA) e de corpo vazio (PCV) dos componentes externos de cabritos, de acordo com o tratamento e genótipo

\begin{tabular}{|c|c|c|c|c|c|c|c|c|c|}
\hline \multirow[t]{2}{*}{ Variável } & \multirow[t]{2}{*}{ Média } & \multicolumn{2}{|c|}{ Tratamento } & \multicolumn{3}{|c|}{ Genótipo $^{1}$} & \multicolumn{2}{|c|}{$\begin{array}{c}\text { Nível de } \\
\text { significância }^{2}\end{array}$} & \multirow[t]{2}{*}{$\mathrm{CV}^{3}$} \\
\hline & & controle & rbST & ALP & $1 / 2 \mathrm{BA}$ & $3 / 4 \mathrm{BA}$ & $\mathrm{T}$ & $\mathrm{G}$ & \\
\hline Cabeça, kg & 1,59 & 1,54 & 1,65 & 1,57 & 1,65 & 1,60 & NS & NS & 12,57 \\
\hline Cabeça, \%PVA & 6,16 & 6,14 & 6,18 & $5,75 \mathrm{~b}$ & $6,05 \mathrm{ab}$ & $6,50 \mathrm{a}$ & NS & $*$ & 9,23 \\
\hline Cabeça, \%PCV & 6,92 & 6,88 & 6,96 & $6,43 b$ & $7,01 \mathrm{ab}$ & $7,24 \mathrm{a}$ & NS & $*$ & 8,81 \\
\hline Patas, kg & 0,82 & 0,79 & 0,85 & 0,85 & 0,85 & 0,79 & NS & NS & 14,22 \\
\hline Patas, \%PVA & 3,15 & 3,16 & 3,16 & 3,11 & 3,12 & 3,20 & NS & NS & 6,20 \\
\hline Patas, \%PCV & 3,54 & 3,53 & 3,56 & 3,48 & 3,62 & 3,56 & NS & NS & 6,98 \\
\hline Pele, kg & 1,91 & 1,86 & 1,95 & 1,90 & 2,05 & 1,86 & NS & NS & 19,16 \\
\hline Pele, \%PVA & 7,31 & 7,32 & 7,30 & 6,95 & 7,48 & 7,51 & NS & NS & 12,67 \\
\hline Pele, \%PCV & 8,21 & 8,20 & 8,22 & 7,78 & 8,63 & 8,37 & NS & NS & 12,31 \\
\hline Total, kg & 4,32 & 4,19 & 4,44 & 4,31 & 4,55 & 4,25 & NS & NS & 14,11 \\
\hline Total, \%PVA & 16,62 & 16,61 & 16,64 & 15,81 & 16,64 & 17,21 & NS & NS & 7,23 \\
\hline Total, \%PCV & 18,69 & 18,61 & 18,73 & $17,68 \mathrm{~b}$ & $19,26 \mathrm{a}$ & $19,18 \mathrm{ab}$ & NS & $*$ & 6,90 \\
\hline
\end{tabular}

${ }^{1}$ ALP: raça Alpina; 1/2 BA: 1/2 Boer + 1/2 Alpina; 3/4 BA: 3/4 Boer + 1/4 Alpina. ${ }^{2}$ T: tratamento; G: genótipo. ${ }^{3}$ Coeficiente de variação. NS: não significativo $(\mathrm{P}>0,05) ; *$ : $\mathrm{P}<0,05$.

As proporções de cabeça em relação ao PVA e ao PCV foram influenciadas pelo genótipo (Tabela 3). Os animais $3 / 4$ BA apresentaram maiores valores em relação aos animais da raça Alpina e os $1 \frac{1}{2} \mathrm{BA}$ foram semelhantes aos demais genótipos. Este resultado pode ser explicado pelo fato de os animais
3/4 BA apresentarem maior proporção de sangue da raça Boer, que apresenta como característica cabeças pesadas (SKINNER, 1972). Resultado semelhante aos de CAMERON et al. (2001), que observaram maior proporção de cabeça em animais Boer $\mathrm{x}$ Spanish e Boer x Angorá em relação aos da raça 
Spanish.

Dos não-componentes externos da carcaça, a pele apresentou maior proporção $(8,21 \%)$ em relação aos demais (Tabela 3). Isso pode representar um retorno financeiro ao produtor, uma vez que a pele apresenta expressivo valor comercial. DHANDA et al. (1999) observaram uma proporção de 7,3\% de pele em relação ao PCV para animais Boer $\mathrm{x}$ Angorá.

Os pesos de cabeça, patas e pele, denominados de descarte duro, representam de 15 a $17 \%$ do peso vivo do animal. No presente estudo, representaram cerca de 17\% (Tabela 3). De acordo com CARVALHO et al. (2003), quanto menor for o peso desses componentes, maior será o rendimento da carcaça.

A proporção total dos não-componentes externos da carcaça em relação ao PCV foi influenciada pelo genótipo (Tabela 3). Os animais 1/2 BA apresentaram maiores valores em relação aos animais da raça Alpina e os $3 / 4$ BA foram semelhantes aos demais. Este resultado é devido às maiores proporções de patas e pele dos animais $1 / 2$ BA.

Na Tabela 4 estão apresentados os valores médios para órgãos vitais de cabritos. Não foi observada influência da interação tratamento e genótipo para nenhuma das variáveis estudadas.

Tabela 4. Médias para pesos expresso em valores absolutos e em porcentagem do peso vivo ao abate (PVA) e de corpo vazio (PCV) de órgãos vitais de cabritos, de acordo com o tratamento e genótipo

\begin{tabular}{|c|c|c|c|c|c|c|c|c|c|}
\hline \multirow[t]{2}{*}{ Variável } & \multirow[t]{2}{*}{ Média } & \multicolumn{2}{|c|}{ Tratamento } & \multicolumn{3}{|c|}{ Genótipo $^{I}$} & \multicolumn{2}{|c|}{$\begin{array}{c}\text { Nível de } \\
\text { significância }^{2}\end{array}$} & \multirow[t]{2}{*}{$\mathrm{CV}^{3}$} \\
\hline & & controle & rbST & ALP & $1 / 2 \mathrm{BA}$ & $3 / 4 \mathrm{BA}$ & $\mathrm{T}$ & $\mathrm{G}$ & \\
\hline Coração, kg & 0,14 & 0,14 & 0,15 & 0,14 & 0,16 & 0,14 & $\mathrm{NS}$ & NS & 19,97 \\
\hline Coração, \%PVA & 0,54 & 0,53 & 0,56 & 0,52 & 0,57 & 0,55 & NS & NS & 9,78 \\
\hline Coração, \%PCV & 0,61 & 0,60 & 0,63 & 0,58 & 0,67 & 0,62 & NS & NS & 9,73 \\
\hline Pulmão, kg & 0,41 & 0,42 & 0,41 & $0,47 \mathrm{a}$ & $0,44 a b$ & $0,36 \mathrm{~b}$ & NS & $*$ & 19,77 \\
\hline Pulmão, \%PVA & 1,59 & 1,65 & 1,53 & 1,72 & 1,62 & 1,48 & NS & NS & 17,39 \\
\hline Pulmão, \%PCV & 1,78 & 1,84 & 1,73 & 1,92 & 1,87 & 1,65 & NS & NS & 17,41 \\
\hline Rins, kg & 0,11 & 0,10 & 0,11 & $0,13 \mathrm{a}$ & $0,11 a b$ & $0,10 \mathrm{~b}$ & NS & $* *$ & 14,18 \\
\hline Rins, \%PVA & 0,42 & 0,41 & 0,43 & 0,47 & 0,40 & 0,40 & NS & NS & 16,71 \\
\hline Rins, \%PCV & 0,47 & 0,46 & 0,48 & $0,52 \mathrm{a}$ & $0,46 a b$ & $0,44 \mathrm{~b}$ & NS & $*$ & 13,07 \\
\hline Fígado, kg & 0,54 & 0,55 & 0,53 & 0,60 & 0,55 & 0,49 & NS & NS & 22,32 \\
\hline Fígado, \%PVA & 2,05 & 2,13 & 1,99 & 2,20 & 2,00 & 1,97 & NS & NS & 12,65 \\
\hline Fígado, \%PCV & 2,31 & 2,38 & 2,24 & 2,47 & 2,30 & 2,19 & NS & NS & 12,01 \\
\hline Baço, kg & 0,04 & 0,04 & 0,04 & 0,05 & 0,04 & 0,04 & NS & NS & 16,30 \\
\hline Baço, \%PVA & 0,16 & 0,16 & 0,15 & $0,18 \mathrm{a}$ & $0,16 a b$ & $0,14 \mathrm{~b}$ & NS & $*$ & 19,88 \\
\hline Baço, \%PCV & 0,18 & 0,18 & 0,17 & $0,20 \mathrm{a}$ & $0,18 \mathrm{ab}$ & $0,16 b$ & NS & $*$ & 18,64 \\
\hline Total, kg & 1,25 & 1,25 & 1,25 & $1,39 a$ & $1,30 \mathrm{ab}$ & $1,13 b$ & NS & $*$ & 16,93 \\
\hline Total, \%PVA & 4,76 & 4,88 & 4,66 & $5,09 a$ & 4,74ab & $4,54 b$ & NS & $*$ & 9,39 \\
\hline Total, \%PCV & 5,35 & 5,47 & 5,24 & $5,69 \mathrm{a}$ & $5,47 \mathrm{ab}$ & $5,06 \mathrm{~b}$ & NS & $*$ & 8,55 \\
\hline
\end{tabular}

${ }^{1}$ ALP: raça Alpina; $1 / 2$ BA: 1/2 Boer + 1/2 Alpina; 3/4 BA: $3 / 4$ Boer + 1/4 Alpina. ${ }^{2}$ T: tratamento; G: genótipo. ${ }^{3}$ Coeficiente de variação. NS: não significativo $(\mathrm{P}>0,05) ; *: \mathrm{P}<0,05 ; * *: \mathrm{P}<0,01$.

O tratamento não influenciou nenhuma das variáveis estudadas. Resultados contrários aos relatados por SKARDA (1998) e EARLY et al. (1990) que observaram fígado com maior peso nos em caprinos e em bovinos tratados, respectivamente, o que pode refletir um aumento no metabolismo deste órgão devido à aplicação deste hormônio. No presente estudo, contudo, dosagem utilizada não parece ter sido suficiente para causar este efeito.

$\mathrm{O}$ genótipo não influenciou o peso e as proporções em relação ao PVA e PCV do coração e fígado (Tabela 4). Os resultados obtidos podem ser explicados pelo fato de os animais apresentarem idade, peso inicial e ao abate próximos, podendo-se inferir que o desenvolvimento dos órgãos também está ligado ao tamanho do animal. Segundo TONETTO et al. (2004), a semelhança dos pesos e percentuais de órgãos de crescimento precoce, entre eles o coração e o fígado, decorre da necessidade fisiológica de o animal desenvolver estes órgãos para sua sobrevivência. Esse resultados são semelhantes aos de GIBB et al. (1993) e DHANDA et al. (1999), que não observaram a influência de diferentes genótipos ao avaliarem as proporções de fígado e coração.

Os pesos do pulmão e rins foram 
influenciados pelo genótipo (Tabela 4). Os animais da raça Alpina apresentaram maiores valores em relação aos animais 3/4 BA. Este resultado sugere que raças com ascendência leiteira apresentam maior peso relativo de pulmões em relação às raças de corte. Resultado semelhante ao de FERREL et al. (1976) que observaram que os intestinos, fígado, coração e rins de novilhas leiteiras (Jersey) são, proporcionalmente, maiores que os de novilha de corte (Hereford). CARVALHO et al. (2003) verificaram em bovinos maior peso relativo de pulmões, rúmen-retículo, fígado, coração, pulmões e baço nas raças com aptidão leiteira comparadas às raças de corte.

As proporções de rins (em relação ao $\mathrm{PCV}$ ) e baço (em relação ao PVA e PCV) foram influenciados pelo genótipo (Tabela 4). Os animais da raça Alpina apresentaram maiores valores em relação aos animais $3 / 4$ BA. Segundo SILVA SOBRINHO et al. (2003), o baço é pouco representativo economicamente e a maioria dos varejistas o comercializam junto com o fígado.
MATTOS et al. (2006) observaram valores médios de $0,06 \mathrm{~kg}$ e $0,30 \%$ PCV para os rins em animais Moxotó e Canindé.

Existem diferenças entre genótipos quanto ao modelo de desenvolvimento ou velocidade de formação dos órgãos e dos tecidos que constituem a massa do corpo. Essa velocidade de desenvolvimento pode ser afetada pelo tamanho do corpo adulto e hormônios (JORGE \& FONTES, 2001), pela idade e por causas ambientais (COLEMAN et al., 1993).

$\mathrm{Na}$ Tabela 5 estão apresentados os valores médios para sangue, trato gastrintestinal vazio, gordura interna e peri-renal de cabritos. Não foi observada influência da interação tratamento e genótipo para nenhuma das variáveis estudadas.

$\mathrm{O}$ tratamento não influenciou nenhuma das variáveis estudadas. Esses resultados são contrários aos de EARLY et al. (1990) que ao avaliarem bovinos, não constataram efeito do rbST na proporção de gordura peri-renal.

Tabela 5. Médias para pesos expresso em valores absolutos e em porcentagem do peso vivo ao abate (PVA) e de corpo vazio (PCV) de sangue, trato gastrintestinal vazio (TGIv), gordura interna (GOI) e gordura perirenal (GOP) de cabritos, de acordo com o tratamento e o genótipo

\begin{tabular}{|c|c|c|c|c|c|c|c|c|c|}
\hline \multirow[t]{2}{*}{ Variável } & \multirow[t]{2}{*}{ Média } & \multicolumn{2}{|c|}{ Tratamento } & \multicolumn{3}{|c|}{ Genótipo $^{1}$} & \multicolumn{2}{|c|}{$\begin{array}{c}\text { Nível de } \\
\text { significância }\end{array}$} & \multirow[t]{2}{*}{$\mathrm{CV}^{3}$} \\
\hline & & controle & $\mathrm{rbST}$ & ALP & $1 / 2 \mathrm{BA}$ & $3 / 4 \mathrm{BA}$ & $\mathrm{T}$ & $\mathrm{G}$ & \\
\hline Sangue, kg & 1,16 & 1,16 & 1,16 & $1,31 \mathrm{a}$ & $1,17 \mathrm{ab}$ & $1,05 \mathrm{~b}$ & NS & $* *$ & 14,33 \\
\hline Sangue, \%PVA & 4,46 & 4,59 & 4,33 & $4,79 \mathrm{a}$ & $4,30 \mathrm{ab}$ & $4,27 \mathrm{~b}$ & NS & $*$ & 7,57 \\
\hline Sangue, PCV & 5,01 & 5,14 & 4,88 & $5,36 \mathrm{a}$ & $4,99 \mathrm{ab}$ & $4,76 b$ & NS & $* *$ & 6,23 \\
\hline TGIv, kg & 2,34 & 2,31 & 2,36 & $2,59 a$ & $2,25 \mathrm{ab}$ & $2,18 \mathrm{~b}$ & NS & $*$ & 15,12 \\
\hline TGIv, \%PVA & 8,97 & 9,09 & 8,87 & 9,50 & 8,23 & 8,86 & NS & NS & 10,73 \\
\hline TGIv, \%PCV & 10,07 & 10,18 & 9,97 & 10,62 & 9,50 & 9,88 & NS & NS & 10,29 \\
\hline GOI, kg & 0,42 & 0,41 & 0,43 & $0,60 \mathrm{a}$ & $0,45 a b$ & $0,29 b$ & NS & $* *$ & 39,86 \\
\hline GOI, \%PVA & 1,55 & 1,55 & 1,55 & $2,17 \mathrm{a}$ & $1,55 \mathrm{ab}$ & $1,10 \mathrm{~b}$ & NS & $* *$ & 29,77 \\
\hline GOI, \%PCV & 1,75 & 1,74 & 1,76 & $2,43 \mathrm{a}$ & $1,78 \mathrm{ab}$ & $1,25 b$ & NS & $* *$ & 31,07 \\
\hline GOP, kg & 0,15 & 0,16 & 0,15 & $0,20 \mathrm{a}$ & $0,18 \mathrm{ab}$ & $0,11 \mathrm{~b}$ & NS & $*$ & 52,48 \\
\hline GOP, \%PVA & 0,56 & 0,60 & 0,53 & $0,73 \mathrm{a}$ & $0,62 \mathrm{ab}$ & $0,43 b$ & NS & $*$ & 43,41 \\
\hline GOP, \%PCV & 0,63 & 0,67 & 0,60 & $0,81 \mathrm{a}$ & $0,71 \mathrm{ab}$ & $0,48 b$ & NS & $*$ & 42,82 \\
\hline
\end{tabular}

${ }^{1}$ ALP: raça Alpina; 1/2 BA: 1/2 Boer + 1/2 Alpina; 3/4 BA: 3/4 Boer + 1/4 Alpina. ${ }^{2}$ T: tratamento; G: genótipo. ${ }^{3}$ Coeficiente de variação. NS: não significativo $(\mathrm{P}>0,05) ; *$ : $\mathrm{P}<0,05 ; * *: \mathrm{P}<0,01$.

Observou-se influência do genótipo no peso e proporções (em relação ao PVA e PCV) do sangue. Os animais da raça Alpina apresentaram maiores valores em relação aos animais $3 / 4$ Boer. Os cabritos $1 / 2$ BA foram semelhantes aos dois genótipos. Os resultados do presente trabalho foram superiores aos de MATTOS et al. (2006) que observaram valores médios de $0,80 \mathrm{~kg}$ e $4,29 \%$ PCV do sangue em animais Moxotó e Canindé.

$\mathrm{O}$ peso do trato gastrintestinal vazio (TGIv) foi influenciado pelo genótipo. Os animais da raça Alpina apresentaram maior peso do TGIv quando comparados com os animais $3 / 4$ Boer, provavelmente porque os animais da raça Alpina em virtude de sua seleção ter sido direcionada, principalmente, para produção de leite, exige maior consumo de alimentos. PERON et al. (1993) observaram que animais da raça Holandesa apresentaram maior peso do trato gastrintestinal vazio (estômago e intestino) que as raças especializadas para corte. Entretanto, 
DHANDA et al. (1999) e CAMERON et al. (2001), ao avaliarem caprinos de diferentes genótipos, não observaram influência no peso do TGIv.

A distribuição da gordura na carcaça caprina apresenta-se bem diferente das outras espécies de ruminantes, como os ovinos, pois no processo de evisceração a maior parte dela é extraída. Cerca de $45 \%$ da gordura corporal é armazenada nas vísceras e, em bovinos e ovinos, esse valor é de somente $25 \%$ (POTCHOIBA et al., 1990).

Observou-se influência do genótipo no peso e proporções (em relação ao PVA e PCV) de gordura interna e peri-renal. Os animais da raça Alpina apresentaram maiores valores em relação aos animais $3 / 4$ Boer. Este resultado demonstra que os animais da raça Alpina apresentaram maior habilidade fisiológica que os $3 / 4 \mathrm{BA}$ em depositar gordura intra-abdominal. A maior gordura visceral em animais de aptidão leiteira resultaria, na prática, em maiores exigências de energia para mantença, em virtude da maior atividade metabólica do tecido adiposo interno em relação ao tecido adiposo periférico (THOMPSON et al., 1983; SOLIS et al., 1988). KOSUM et al. (2003) observaram maior proporção de gordura interna (\%PCV) em animais Saanen em relação aos animais da raça Bornova.

\section{CONCLUSÕES}

A utilização da somatotropina bovina recombinante (rbST) na dosagem de $0,3 \mathrm{mg} / \mathrm{kg}$ de peso vivo em cabritos da raça Alpina, $1 / 2$ Boer e $3 / 4$ Boer não alterou o peso e as proporções dos não-componentes da carcaça. As proporções e os pesos dos nãocomponentes da carcaça variaram em função dos genótipos, embora abatidos a pesos vivos semelhantes. Os animais da raça Alpina apresentaram maior habilidade fisiológica que os mestiços Boer em depositar gordura interna.

\section{REFERÊNCIAS}

AMIN, M.R.; HUSAIN, S.S.; ISLAM, A.B.M.M. Evaluation of Black Bengal goats and their cross with the Jamunapari breed for carcass characteristics. Small Ruminant Research, v.38, p.211-215, 2000.

CAMERON, M.R.; LUO, J.; SAHLU, T.; HART, S.P.; COLEMAN, S.W.; GOETSCH, A.L. Growth and slaughter traits of Boer x Spanish, Boer x Angora, and Spanish goats consuming a concentrate-based diet. Journal of Animal Science, v.79, p.1423-1430, 2001.

CARVALHO, P.A.; SANCHEZ, L.M.B.; VIÉGAS, J.; VELHO, J.P.; JAURIS, G.C.; RODRIGUES, M.B. Componentes do peso vivo e órgãos viscerais de bezerros machos de origem leiteira ao nascimento, 50 e 110 dias de vida. Revista Brasileira de Zootecnia, v.32, n.6, p.14691475, 2003.

COLEMAN, S.W.; EVANS, B.C.; GUENTHER, J.J. Body and carcass composition of Angus and Charolais steers as affected by age and nutrition. Journal of Animal Science, v.71, n.1, p.86-95, 1993.

COSTA, R.G.; PIMENTA FILHO, E.C.; MOREIRA, R.T.; RODRIGUES, A. Rendimento de carcaça e vísceras em caprinos mestiços Anglo-Nubianos. Agropecuária Técnica, v.11, n.1/2, p.1-8, 1990.

DELFA, R.; GONZALES, C.; TEIXEIRA, A. El "quinto quarto". Revista Ovis. n.17, p.49-66, 1991.

DHANDA, J.S.; TAYLOR, D.G.; McCOSKER, J.E.; MURRAY, P.J. The influence of goat genotype on the production of Capretto and Chevon carcasses. 1. Growth and carcass characteristics. Meat Science, v.52, p.355361, 1999.

EARLY, R.J.; McBRIDE, B.W.; BALL, R.O. Growth and metabolism in somatotropin-treated steers: II. Carcass and noncarcass tissue components and chemical composition. Journal of Animal Science, v.68, p.4144-4152, 1990.

FATURI, C.; RESTLE, J.; BRONDANI, I.L.; SILVA, J.H.S.; ARBOITTE, M.Z.; CARRILHO, C.O.; PEIXOTO, L.A.O. Características da carcaça e da carne de novilhos de diferentes grupos genéticos alimentados em confinamento com diferentes proporções de grão de aveia e grão de sorgo no concentrado. Revista Brasileira de Zootecnia, v.31, n.5, p.2024-2035, 2002.

FERREL, C.L.; GARRET, W.N.; HINMAN, N. Estimation of body in pregnant and non pregnant heifers.Journal of Animal Science, v.42, p.1158-1166, 1976.

GALLO, C.; LE BRETON, Y.; WAINNRIGHT, I.; BERKHOFF, M. Body and carcass composition of male and female Criollo goats in the South of Chile. Small Ruminant Research, v.23, p.163-169, 1996.

GIBB, M.J.; COOK, J.E.; TREACHER, T.T. Performance of British Saanen, Boer x British Saanen and AngloNubian castrated male kids from 8 weeks to slaughter at 28, 33 or $38 \mathrm{~kg}$ live weight. Animal Production, v.57, p.263-271, 1993.

JORGE, A.M.; FONTES, C.A.A. Desenvolvimento relativo das partes do corpo de zebuínos de quatro raças. Ciência Rural, v.31, n.5, p.857-881, 2000.

KIRTON, A.H.; CARTER, A.H.; CLARCKE, J.N.; SINCLAIR, D.P.; MERCER, G.J.K.; DUGANZICH, D.M. A comparison between 15 ram breeds for export lamb production. 1. Live weights, body components, carcass measurements and compositions. New Zealand Journal of Agricultural Research, v.38, p.347-360, 1995.

KOSUM, N.; ALCICEK, A.; TASKIN, T.; ÖNENÇ, A. Fattening performance and carcass characteristics of Saanen and Bornova male kids under an intensive management system. Czech Journal of Animal Science, 
v.48, n.9, p.379-386, 2003.

MATTOS, C.W.; CARVALHO, F.F.R.; DUTRA JÚNIOR, W.M.; VÉRAS, A.S.C.; BATISTA, A.M.V.; ALVES, K.S.; RIBEIRO, V.L.; SILVA, M.J.M.S.; MEDEIROS, G.R.; VASCONCELOS, R.M.J.; ARAÚJO, A.O.; MIRANDA, S.B. Características de carcaça e dos componentes não-carcaça de cabritos Moxotó e Canindé submetidos a dois níveis de alimentação. Revista Brasileira de Zootecnia, v.35, n.5, p.2125-2134, 2006.

MENEZES, J.J.L.; GONÇALVES, H.C.; RIBEIRO, M.S.; RODRIGUES, L.; CAÑIZARES, G.I.L.; MEDEIROS, B.B.L. Efeitos do sexo, do grupo racial e da idade ao abate nas características de carcaça e maciez da carne de caprinos. Revista Brasileira de Zootecnia, v.38, n.9, p.1769-1778, 2009.

MISSIO, R.L.; BRONDANI, I.L.; RESTLE, J.; SILVA, J.H.S.; SILVEIRA, M.F.; SILVA, V.S. Partes nãointegrantes da carcaça de tourinhos alimentados com diferentes níveis de concentrado na dieta. Revista Brasileira de Zootecnia, v.38, n.5, p.906-915, 2009.

NATIONAL RESEARCH COUNCIL - NRC 2001. Nutrient Requirements of Dairy Cattle. 7.ed. Washington: National Academic Press, 2001. 387p.

OSÓRIO J.C.; JARDIM, P.O.; PIMENTEL, M.; POUEY, J.; LÜDER, W.E.; ÁVILA, C.J. Componentes do peso vivo em cordeiros da raça Corriedale. Ciência Rural, v.26, n.3, p.483-487, 1996.

PEÑA, F.; PEREA, J.; GARCÍA, A.; ACERO, R. Effects of weight at slaughter and sex on the carcass characteristics of Florida suckling kids. Meat Science, v.75, p.543-550, 2007.

PEREZ, P.; MAINO, M.; MORALES, M.S.; SOTO, A. Effect of goat and milk substitutes and sex on productive parameters and carcass composition of Creole kids. Small Ruminant Research, v.42, p.87-93, 2001.

PERON, A.J.; FONTES, C.A.A; LANA, R.P.; SILVA, D.J.; QUEIROZ, A.C.; PAULINO, M.F. Tamanho dos órgãos internos e distribuição da gordura corporal em novilhos de cinco grupos genéticos, submetidos à alimentação restrita e "ad libitum". Revista Brasileira de Zootecnia, v.22, n.5, p.813-819, 1993.

POTCHOIBA, M.J.; LU, C.D.; PINKERTON, F.; SAHLU, T. Effects of all-milk diet on weight gain, organ development, carcass characteristics and tissue composition, including fatty acids and cholesterol contents, of growing male goats. Small Ruminant
Research, v.3, p.583-592, 1990.

SILVA SOBRINHO, A.G.; GASTALDI, K.A.; GARCIA, C.A.; MACHADO, M.R.F. Diferentes dietas e pesos ao abate na produção de órgãos de cordeiros. Revista Brasileira de Zootecnia, v.32, n.6, p.1792-1799, 2003 (supl.1).

SILVA, D.J., QUEIROZ, A.C. Análise de alimentos Métodos químicos e biológicos. Viçosa: Universidade Federal de Viçosa, 2002. 235p.

SKARDA, J. Effects of bovine growth hormone on growth, organ weights, tissue composition and adipose tissue metabolism in young castrated male goats. Livestock Production Science, v.55, p.215-225, 1998.

SKINNER, J.D. Utilization of the Boer goat for intensive animal production. Tropical Animal Health and Production, v.4, p.120-128, 1972.

SNIFFEN, C.J.; O'CONNOR, D.G.; VAN SOEST, P.J.; FOX, D.G.; RUSSELL, J.B. A net carbohydrate and protein system for evaluating cattle diets: II Carbohydrate and protein avaibility. Journal of Animal Science, v.70, p.3562-3577, 1992.

SOLIS, J.C.; BYERS, F.M.; SCHELLING, G.T.; LONG, C.R.; GREENE, L.W. Maintenance requirements and energetic efficiency of cows of different breed types. Journal of Animal Science, v.66, p.764-773, 1988.

THOMPSON, W.R.; MEISKE, J.C.; GOODRICH, R.D.; RUST, J.R.; BYERS, F.M. Influence of body composition on energy requirements of beef cows during winter. Journal of Animal Science, v.56, n.5, p.1241-1252, 1983.

TONETTO, C.J.; PIRES, C.C.; MÜLLER, L.; ROCHA, C.G.; SILVA, J.H.S.; FRESCURA, R.B.M.; KIPPERT, C.J. Rendimentos de cortes da carcaça, características da cerne e componentes do peso vivo em cordeiros terminados em três sistemas de alimentação. Revista Brasileira de Zootecnia, v.33, n.1, p.234-241, 2004.

UNIVERSIDADE FEDERAL DE VIÇOSA - UFV. Sistema de análises estatísticas e genéticas - SAEG. Versão 8.0. Viçosa, 2000. 142 p.

ZAINUIR, A.S.; TASSELL, R.; KELLAWAY, R.C.; DODEMAIDE, W.R. Recombinant growth hormone in growing lambs: effects on growth, feed utilization, body and carcass characteristics on wool growth. Australian Journal of Agricultural Research, v.40, p.195-206, 1989. 